\title{
Understanding the El Niño-Southern Oscillation and Its Interactions with the Indian Ocean and Monsoon
}

\author{
Jin-Yi Yu \\ Department of Earth System Science, University of California, Irvine, California, USA \\ jyyu@uci.edu
}

\begin{abstract}
The Pacific and Indian Oceans are closely linked to each other through atmospheric circulation and oceanic throughflow. Climate variations in one ocean basin often interact with those in the other basin. This includes phenomena such as the El Niño-Southern Oscillation (ENSO), biennial monsoon variability, and the Indian Ocean zonal/dipole mode. Increasing evidence suggests that these interbasin interactions and feedbacks are crucial in determining the period, evolution, and pattern of ENSO and its decadal variability. This article reviews recent efforts in using a series of basin-coupling CGCM (coupled atmosphere-ocean general circulation model) experiments to understand the physical processes through which ENSO interacts with the Indian Ocean and monsoon, the impacts of interbasin interactions on the characteristics of ENSO, the relative roles of the Pacific and Indian Oceans in monsoon variability, and ENSO's role in the Indian Ocean zonal/dipole mode.
\end{abstract}

\section{Introduction}

The Pacific Ocean exhibits prominent sea surface temperature (SST) variations on time scales that range from interannual to interdecadal. The interannual fluctuations are primarily associated with the El Niño-Southern Oscillation (ENSO), which results from the interactions between the tropical Pacific Ocean and the overlying atmosphere (Bjerknes, 1969). Warm (El Niño) and cold (La Niña) ENSO events occur quasi-periodically and are generally associated with significant anomalies in global and regional climate patterns. The fundamental physical processes that give rise to ENSO are believed to reside within the tropical Pacific. ENSO research over the past few decades has focused mainly on the tropical Pacific Ocean, and has resulted in a significant understanding of this climate phenomenon. Coupled atmosphere-ocean models that include only the tropical Pacific Ocean have obtained encouraging success in ENSO simulations and prediction (e.g. Cane and Zebiak, 1985; Cane et al., 1986; Schopf and Suarez, 1988; Battisti and Hirst, 1989; Delecluse et al., 1998; Latif et al., 2001; Yu and Mechoso, 2001).

Nevertheless, variations originating from the Indian Ocean and monsoons, such as weak and strong summer monsoons, interannual variability in the Indian Ocean SST, and volume fluctuations in the oceanic throughflow, are also potentially significant in the interaction of ENSO dynamics. The rising zone of the transverse and lateral circulation components of the Indian monsoon coincides with the ascending branch of the Walker circulation (Webster et al., 1992). Variations in the strength of the monsoon can affect Pacific trade winds and, consequently, the period and magnitude of ENSO (Barnett, 1984; Wainer and Webster, 1996). In the ocean, ENSO manifests itself as a zonal displacement of warm water between the western and eastern tropical Pacific. The warm water pool 
in the western Pacific is connected to the eastern Indian Ocean through the Indonesian throughflow. This throughflow is widely known, on average, to carry warm and fresh Pacific waters through the Indonesian archipelago into the Indian Ocean. This leakage of upper ocean waters from the western Pacific to the Indian Ocean acts as a major heat sink for the Pacific Ocean and a heat source for the Indian Ocean (Godfrey, 1996). There were studies suggesting that the throughflow could affect the mean climate state of the tropical Pacific, such as its mean thermocline depth and zonal temperature gradients (Hirst and Godfrey, 1993; Murtugudde et al., 1998; Lee et al., 2002). Since ENSO's period and growth rate depend on the mean climate state over the Pacific (Fedorov and Philander, 2000), the throughflow provides another possible mechanism for the Indian Ocean to affect ENSO activity.

On the other hand, it is known that ENSO events have profound influences on the Indian monsoon (see Shukla and Paolino, 1983; Klein et al., 1999). The relationship between ENSO and the Indian monsoon has long been an area of extensive research. The cause-andeffect relationship between ENSO and one of the strongest interannual signals of the monsoon variability, the tropospheric biennial oscillation (TBO), is still not yet fully understood. The TBO is referred to as the tendency for strong and weak monsoons to flipflop back and forth from year to year (Mooley and Parthasarathy, 1984; Yasunari, 1990; Clarke et al., 1998; Webster et al., 1998; Meehl and Arblaster, 2002). It has been associated with SST anomalies in both the tropical Pacific and the Indian ocean (Rasmusson and Carpenter, 1982; Meehl, 1987; Kiladis and van Loon, 1988; Ropelewski et al., 1992; Lau and Yang, 1996; Meehl and Arblaster, 2002). The associated SST anomalies in the Pacific Ocean are characterized by an ENSO-type pattern with a biennial ( $\sim 2$ years $)$ periodicity. This association leads one to conclude that the TBO and the biennial ENSO component may be related. Some studies suggested that the TBO is forced by the biennial component of ENSO (e.g. Fasullo, 2004), but others argued that it has its own dynamics that are independent of ENSO (e.g. Li et al., 2006).

The relationship between ENSO and the monsoon variations is further complicated by the existence of significant interannual variability in the Indian Ocean SST. The variability may be intrinsic to the coupled Indian Ocean-monsoon system, or remotely forced by ENSO. An increasing number of recent studies suggest that the Indian Ocean may play an active role in influencing ENSO characteristics (e.g. Yu et al., 2000; Yu et al., 2003; Yu, 2005; $\mathrm{Wu}$ and Kirtman, 2004; Kug and Kang, 2005; Kug et al., 2006; Terray and Dominiak, 2005). It was suggested that the ENSO-forced basin-scale warming/cooling in the Indian Ocean might affect atmospheric circulation in the western Pacific to fasten the turnabout of the ENSO cycle and result in biennial ENSO (Kug and Kang, 2005). It was also postulated that the southeastern Indian Ocean SST anomalies act as persistent remote forcing to promote wind anomalies in the western equatorial Pacific and modulate the regional Hadley circulation in the south Pacific, both of which then affect the evolution of ENSO (Terray and Dominiak, 2005). These recent studies imply that the Indian Ocean may be a necessary part of the ENSO dynamics.

A thorough study of the interactions between ENSO and the Indian Ocean and monsoon is crucial for better understandings and successful forecasts of ENSO and monsoon activity. The complex coupling nature of these ENSOIndian Ocean-monsoon interactions makes it difficult to determine their cause-and-effect relationships using observational analyses alone. Numerical model experiments that can isolate the coupling processes within and external to the Pacific Ocean are useful means for this 
purpose. In the past few years, a basin-coupling modeling strategy has been developed ( $\mathrm{Yu}$ et al., 2002) to perform these types of experiments with coupled atmosphere-ocean general circulation models (CGCM's). This article summarizes the findings obtained from these basin-coupling CGCM experiments.

The article is organized as follows. Section 2 describes the University of California, Los Angeles (UCLA) CGCM used for the experiments and the setup of the basin-coupling experiments. The ENSO cycle simulated by the model and its teleconnection patterns in the Indo-Pacific Oceans are presented in Sec. 3. The influences of the Indian Ocean on the ENSO cycle are then discussed in Sec. 4. ENSO's interactions with the biennial monsoon variability (TBO) are examined in Sec. 5. Section 6 reports the findings on the importance of ENSO influence on Indian Ocean SST variability. Section 7 concludes with a review of new understandings of the interactions between ENSO and the Indian Ocean and monsoon.

\section{Basin-Coupling Modeling Strategy}

The CGCM used in this study consists of the UCLA global atmospheric GCM (AGCM) (Suarez et al., 1983; Mechoso et al., 2000) and the Geophysical Fluid Dynamics Laboratory (GFDL) Modular Ocean Model (MOM) (Bryan, 1969; Cox, 1984; Pacanowski et al., 1991). The AGCM includes the schemes of Deardorff (1972) for the calculation of surface wind stress and surface fluxes of sensible and latent heat, Katayama (1972) for short-wave radiation, Harshvardhan et al. (1987) for longwave radiation, Arakawa and Schubert (1974) for parametrization of cumulus convection, and Kim and Arakawa (1995) for parametrization of gravity wave drag. The model has 15 layers in the vertical (with the top at $1 \mathrm{mb}$ ) and a horizontal resolution of $5^{\circ}$ longitude by $4^{\circ}$ latitude. The MOM includes the scheme of Mellor and Yamada (1982) for parametrization of subgrid-scale vertical mixing by turbulence processes. The surface wind stress and heat flux are calculated hourly by the AGCM, and the daily averages passed to the OGCM. The SST is calculated hourly by the OGCM, and its value at the time of coupling is passed to the AGCM. The ocean model has 27 layers in the vertical with $10 \mathrm{~m}$ resolution in the upper $100 \mathrm{~m}$. The ocean has a constant depth of about $4150 \mathrm{~m}$. The longitudinal resolution is $1^{\circ}$; the latitudinal resolution varies gradually from $1 / 3^{\circ}$ between $10^{\circ} \mathrm{S}$ and $10^{\circ} \mathrm{N}$ to almost $3^{\circ}$ at $50^{\circ} \mathrm{N}$. No flux corrections are applied to the information exchanged by model components.

A series of basin-coupling experiments were performed with the UCLA CGCM. In each of the experiments, the atmosphere-ocean couplings were restricted to a certain portion of the Indo-Pacific Ocean by including only that portion in the ocean model component of the CGCM. Three CGCM experiments were conducted in this study: the Indo-Pacific Run, the Pacific Run, and the Indian Ocean Run. In the Pacific Run, the CGCM includes only the tropical Pacific Ocean in the domain of its ocean model component. The Indian Ocean Run includes only the tropical Indian Ocean in the ocean model domain. The Indo-Pacific Run includes both the tropical Indian and Pacific Oceans in the ocean model domain. Outside the oceanic model domains, SST's and sea-ice distributions for the AGCM are prescribed based on a monthly varying climatology. Figure 1 shows the ocean model domain and the sea/land masks used in each of these experiments and the long-term ( $\sim 50$ years $)$ means of their simulated SST's. All three CGCM runs produce a reasonable SST climatology in the Pacific and Indian Oceans, with a warm pool (SST greater than $28^{\circ} \mathrm{C}$ ) that covers both the tropical western Pacific and eastern Indian Oceans. 
(a) Indian-Ocean CGCM Run

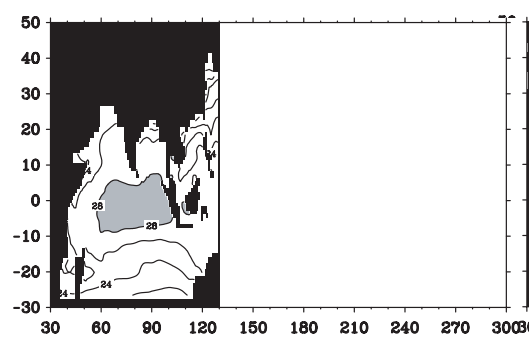

(b) Indo-Pacific CGCM Run

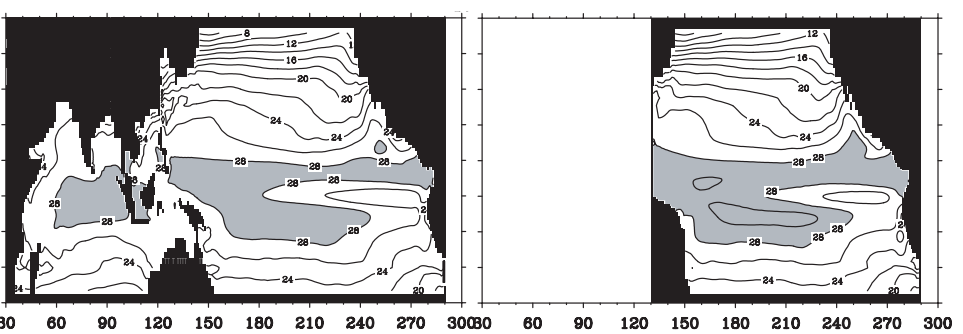

Figure 1. Ocean model domains used in the (a) Indian Ocean Run, (b) Indo-Pacific Run, and (c) Pacific Run. Also shown are the long-term mean SST's produced by these runs. Contour intervals are $2^{\circ} \mathrm{C}$. Values greater than $28^{\circ} \mathrm{C}$ are shaded.

\section{The Simulated ENSO Cycle}

The UCLA CGCM has been shown to produce a realistic seasonal cycle in the tropical eastern Pacific (Yu et al., 1999) and is considered one of the few coupled models capable of producing realistic ENSO simulations in an intercomparison project of ENSO simulation (Latif et al., 2001). The ENSO cycle simulated by the Pacific Run was thoroughly examined by $\mathrm{Yu}$ and Mechoso (2001). It was found that ENSOlike SST variability is produced in the model approximately every 4 years, with a maximum amplitude of about $2^{\circ} \mathrm{C}$. Large westerly wind stress anomalies are simulated to the west of the maximum SST anomalies in all major warm events. A multichannel singular spectrum analysis (M-SSA) (Keppenne and Ghil, 1992) was used to extract the simulated ENSO cycle from the simulation. The M-SSA method has been shown to be capable of extracting nearperiodicity, and their associated spatiotemporal structures, from short and noisy time series (Robertson et al., 1995). Figure 2 shows the structure and evolution of the simulated ENSO cycle as revealed by the leading M-SSA mode along the equator. The ENSO cycle is found to be characterized by predominantly standing oscillations of SST in the eastern Pacific, almost simultaneous zonal wind stress anomalies (a) zonal wind stress

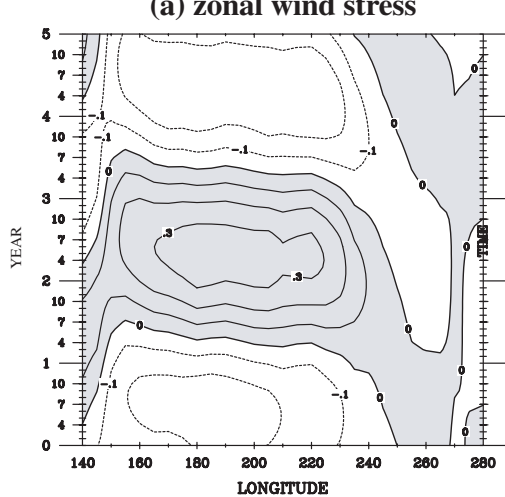

(b) SST

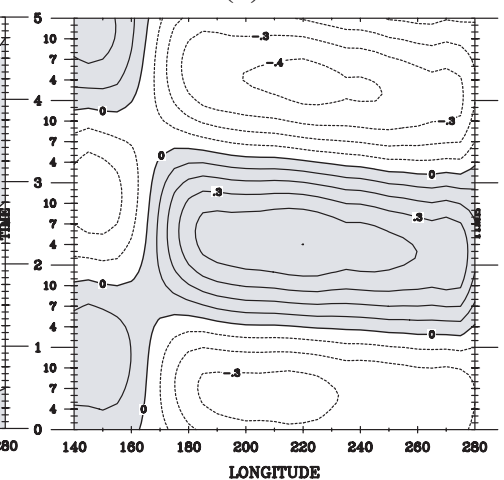

(c) Ocean Heat Content

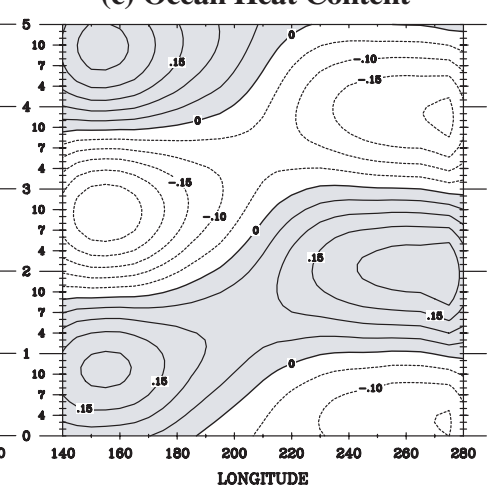

Figure 2. Structures of the simulated ENSO cycle along the equatorial Pacific extracted from the Pacific Run by the M-SSA method. Panel (a) shows the structure of zonal wind stress anomalies, (b) the structure of SST anomalies, and (c) the structure of ocean heat content anomalies. The coordinate is the 61-month (5-year) lag used in the MSSA. Contour intervals are $0.1 \mathrm{dyn} / \mathrm{cm}^{2}$ for (a), $0.10^{\circ} \mathrm{C}$ for (b), and $0.05^{\circ} \mathrm{C}$ for (c). Values shown in (a) are scaled by 10. Positive values are shaded. (From Yu and Mechoso, 2001.) 
(a) zonal-mean component

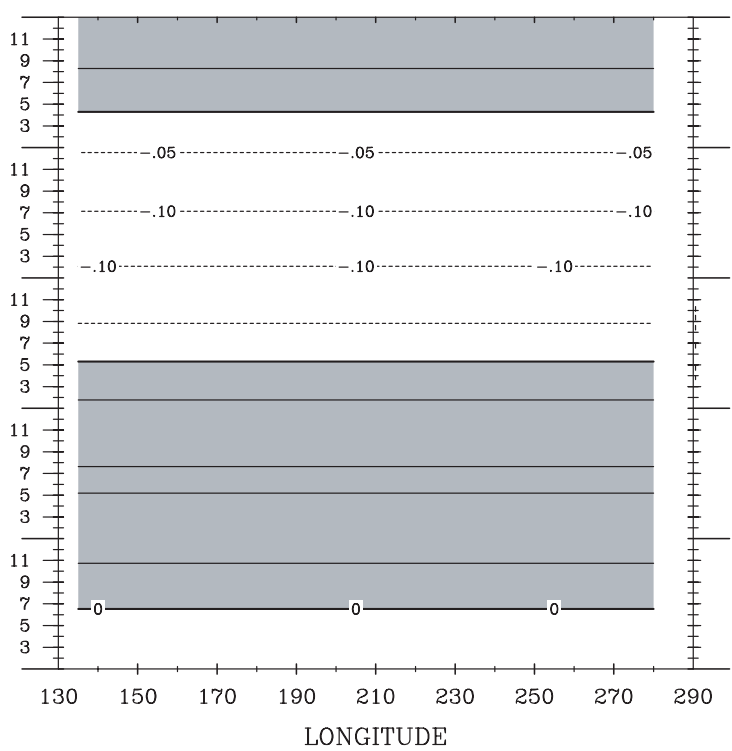

(b) zonally asymmetric component

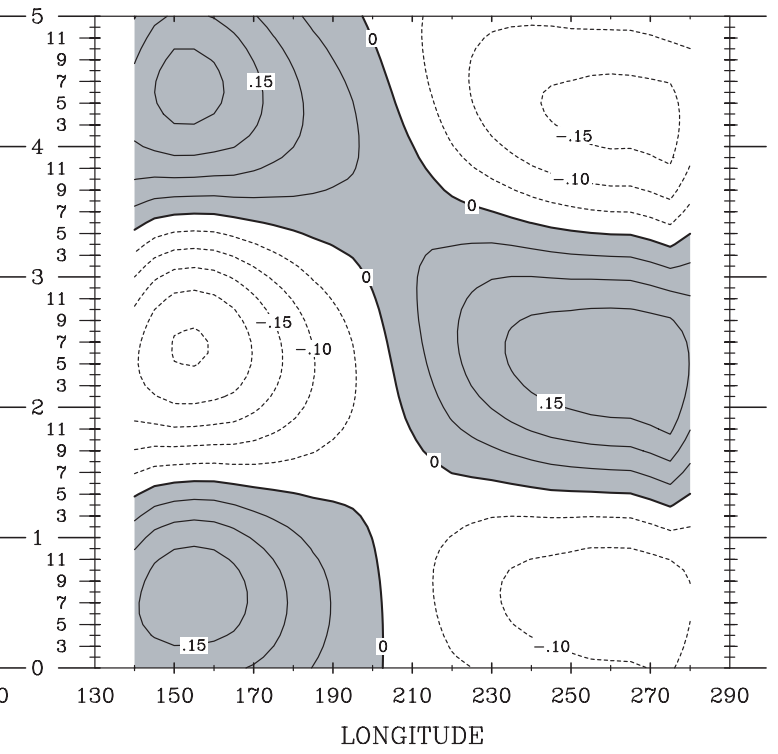

Figure 3. The (a) zonal-mean and (b) zonally asymmetric components of the ocean heat content structure shown in Fig. 2(c). The vertical coordinate spans the 61-month window used in the M-SSA. Contour intervals are $0.05^{\circ} \mathrm{C}$. Positive values are shaded. (From Yu and Mechoso, 2001.)

to the west of the SST anomalies, and preceding ocean heat content anomalies near the eastern edge of the basin. These features are similar to those observed during ENSO events.

The ENSO dynamics in the UCLA CGCM were further examined by focusing on the relationship between SST and ocean heat content (i.e. the memory of ENSO). The ocean heat content is defined as the ocean temperature averaged in the upper $300 \mathrm{~m}$. By separating the ocean heat content anomaly of the M-SSA mode into its zonal-mean and zonally asymmetric components (Fig. 3), it is found that the evolution of the zonal-mean component at the equator is $90^{\circ}$ out of phase with that of the zonally asymmetric component, as well as that of the SST anomaly [compare Fig. 3(a) to Fig. 2(b)]. The onset of the warm ENSO phase occurs at the time when the mean ocean heat content anomaly grows (i.e. recharge) to a maximum value. The ocean heat content anomalies are then removed (i.e. discharge) as the warm phase develops toward its mature stage. This phase lag indicates that the variation in the zonal-mean ocean heat content provides the oscillation memory for the ENSO cycle. The ENSO dynamics in the UCLA CGCM are consistent with the recharge oscillator theory (Wyrtki, 1975; Cane and Zebiak, 1987; Zebiak, 1989; Jin, 1997; Li, 1997). This theory is conceptually similar to the delayed oscillator theory in suggesting the importance of subsurface ocean adjustment processes in producing the needed delay for ENSO oscillation. The recharge oscillator, however, emphasizes the importance of the buildup (i.e. charge) and release (i.e. discharge) of zonal-mean ocean heat content in the equatorial band for the phase reversal of the ENSO cycle.

\section{Teleconnection of ENSO}

By applying the M-SSA to the SST variability produced by the Indo-Pacific Run, it is found 


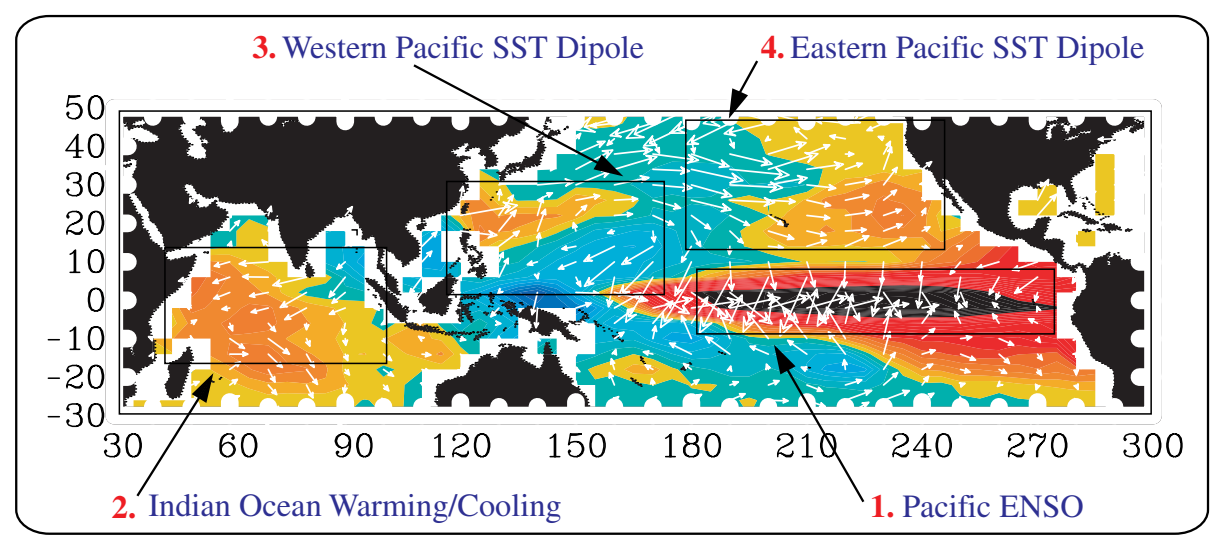

Figure 4. Structures of SST and surface wind stress anomalies of the leading M-SSA mode obtained from the Indo-Pacific Run. Contours represent SST anomalies. Surface wind stress anomalies are indicated by vectors. Contour intervals are $0.1^{\circ} \mathrm{C}$. The structures shown are taken from the mature phase of ENSO in the leading M-SSA mode.

that the simulated ENSO cycle is accompanied by significant SST anomalies in many parts of the Indo-Pacific Ocean. Figure 4 shows the SST anomaly pattern of the leading M-SSA mode (i.e. the ENSO mode) extracted from this run. The major anomaly features in this figure include: (1) the Pacific ENSO, (2) the basinwide warming/cooling in the Indian Ocean, (3) an anomaly dipole in the northwestern Pacific $\left(10^{\circ} \mathrm{N}-30^{\circ} \mathrm{N}\right.$ and $\left.120^{\circ} \mathrm{E}-160^{\circ} \mathrm{E}\right)$, and (4) an anomaly dipole in the northeastern Pacific $\left(10^{\circ} \mathrm{N}-30^{\circ} \mathrm{N}\right.$ and $\left.170^{\circ} \mathrm{E}-120^{\circ} \mathrm{W}\right)$. The basinwide warming (cooling) during an El Niño (La Niña) event is a well-known remote response of the Indian Ocean to ENSO (e.g. Yu an Rienecker, 1999, 2000; Murtugudde et al., 2000) via the "atmospheric bridge" mechanism (Lau and Nath, 1996) or the ENSO-induced tropospheric temperature and moisture variations (Chiang and Sobel, 2002; Neelin et al., 2003). The SST dipole in the northwestern Pacific is accompanied by an anomalous anticyclonic (cyclonic) surface circulation during El Niño (La Niña) and is very similar to the Pacific-East Asia teleconnection pattern discussed by Wang et al. (2000) and Lau and Nath (2006). They suggested that this teleconnection pattern was initially forced by ENSO, and was later maintained by a positive thermodynamic feedback between the circulation anomaly and the ocean mixed layer in the northwestern Pacific.

The northeastern SST anomaly dipole simulated by the CGCM is similar to the zonal SST dipole observed during the 1997-98 ENSO event (Liu et al., 1998), which consisted of centers of anomalous warming along the coast of California and anomalous cooling further to the west in the central Pacific. The question arises as to whether or not the development of this subtropical SST anomaly feature is associated with that of ENSO. Furthermore, if such an association exists, what are the mechanisms that link the two phenomena? $\mathrm{Yu}$ et al. (2000) analyzed the Pacific Run to address these two questions. To concentrate on the relationship between ENSO and this SST dipole, an empirical orthogonal function (EOF) analysis was applied to the model SST anomalies in the Pacific domain between $30^{\circ} \mathrm{S}$ and $50^{\circ} \mathrm{N}$. The leading EOF mode (not shown) is characterized by the ENSO in the tropics and the zonal SST dipole in the subtropics, similar to those shown in the Pacific portion of Fig. 4. 
To examine their relationship, the lagged correlation coefficients were calculated between an index representing the strength of the northeastern Pacific SST dipole and an index representing the intensity of ENSO. The ENSO index is the averaged SST anomalies over the central equatorial Pacific $\left(160^{\circ}-130^{\circ} \mathrm{W}\right.$ and $40^{\circ} \mathrm{S}-40^{\circ} \mathrm{N}$ ), where the simulated SST anomalies are largest in Fig. 4. The dipole index is defined as the difference between the SST anomalies averaged over the eastern center $\left(150^{\circ} \mathrm{W}-\right.$ $130^{\circ} \mathrm{W}$ and $24^{\circ} \mathrm{N}-36^{\circ} \mathrm{N}$ ) of the dipole, and those averaged over the western center $\left(180^{\circ} \mathrm{E}-\right.$ $160^{\circ} \mathrm{W}$ and $24^{\circ} \mathrm{N}-36^{\circ} \mathrm{N}$ ). It was found that the maximum correlation coefficient between these two indices is 0.65 when ENSO leads the dipole by one month. These analyses suggested that the subtropical SST anomaly dipole is forced by ENSO.

To understand the generation mechanism of the SST dipole, Fig. 5 illustrates the relationships between the principal component of the leading EOF mode of SST and the anomalies in sea-level pressure, surface wind stress, and surface heat flux. For the sake of discussion, Fig. 5 is interpreted for the case of a warm ENSO event. Figure 5(a) shows that during El Niño events, the Aleutian Low is enhanced and results in an anomalous cyclonic circulation over the subtropical Pacific. Along the southwesterly branch of the cyclonic circulation, the surface heat flux is reduced [Fig. 5(b)]. This branch brings warm and moist air from the tropics to the subtropics, which is consistent with a reduction in sensible and latent heat flux off the North America coast. Similarly, the northwesterly branch of the cyclonic circulation brings dry and cold air from higher latitudes, which results in increased surface heat flux from the central Pacific. The regions of reduced and enhanced surface heat flux roughly coincide with the warm and cold centers of the subtropical SST anomaly dipole [Fig. 5(c)]. Figure 5, therefore, suggests that the SST anomaly dipole is driven primarily by anomalous surface heat
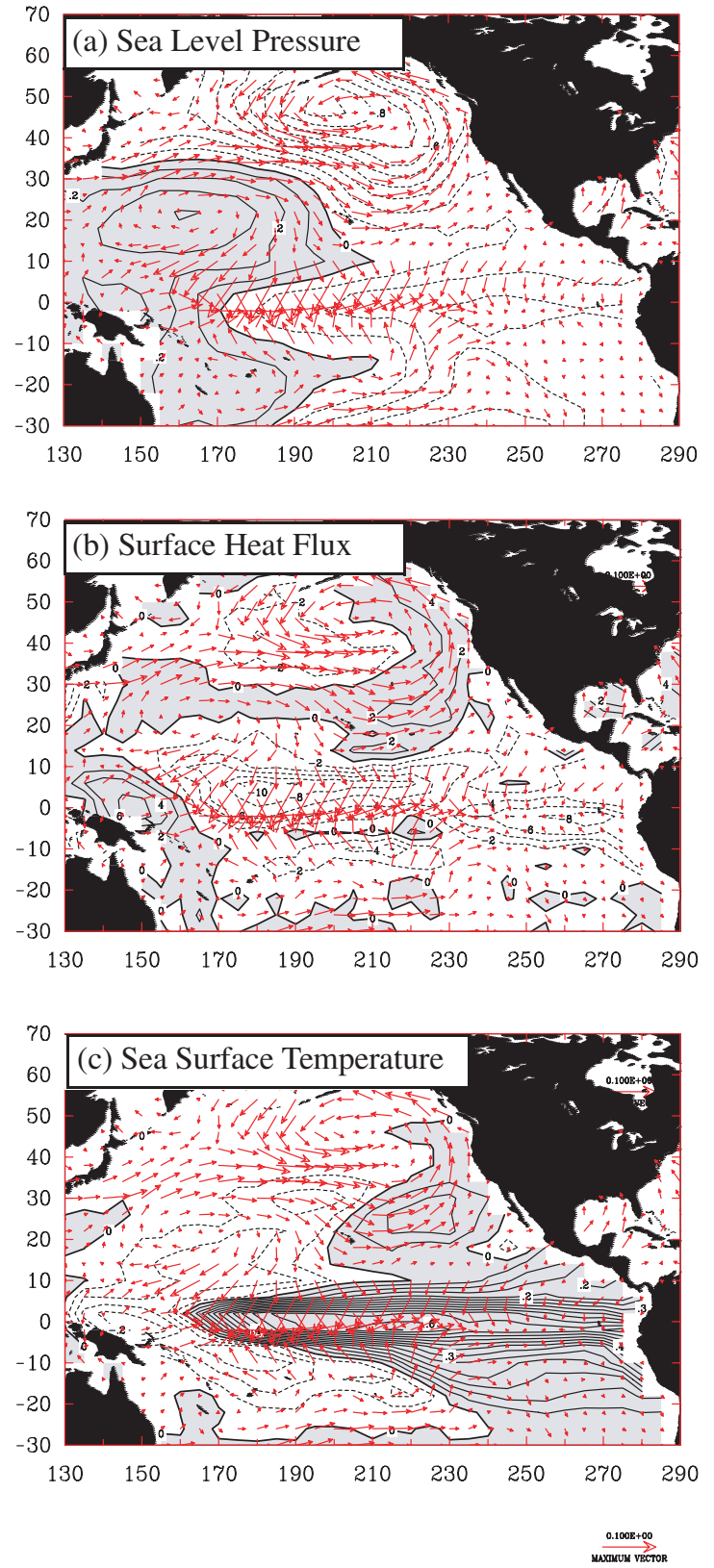

Figure 5. Linear regression between the principal component of the leading EOF mode and the anomalies in (a) sea level pressure, (b) surface heat flux, and (c) SST. Vectors represent regression coefficients between the principal component and zonal and meridional wind stress anomalies and are in units of $\mathrm{dyn} / \mathrm{cm}^{2}$. Contours intervals are $0.1 \mathrm{mb}$ for (a), $0.2 \mathrm{~W} / \mathrm{m}^{2}$ for (b), and $0.05^{\circ} \mathrm{K}$ for $(\mathrm{c})$. Positive values are shaded. Positive (negative) values in (b) indicate less (more) surface heat flux out of the ocean. (From Yu et al., 2000.) 
fluxes associated with the altered atmospheric circulation during ENSO events.

\section{Impacts of Indian Ocean on the ENSO Cycle}

As mentioned earlier, variations in the Indian Ocean may be capable of influencing ENSO activity through either the atmospheric circulation or the oceanic throughflow. To examine this possibility, ENSO simulations were contrasted between the Indo-Pacific Run and the Pacific Run. The former run includes the effects of Indian Ocean SST variability on ENSO, while the latter excludes that effect. Findings obtained from this comparative study were reported by $\mathrm{Yu}$ et al. (2002) and $\mathrm{Yu}$ (2005). It was found that the magnitude and frequency of the ENSO cycle are affected by the addition of an interactive Indian Ocean in the CGCM. Figure 6 compares the time series of the NINO3 index (SST anomalies in $90^{\circ}-150^{\circ} \mathrm{W} ; 5^{\circ} \mathrm{S}-5^{\circ} \mathrm{N}$ ) calculated from the two runs. The first noticeable difference in this figure is that the Indo-Pacific Run produces stronger ENSO amplitudes than the Pacific Run. The standard deviation of the NINO3 SST anomalies is increased from $0.50^{\circ} \mathrm{C}$ for the Pacific Run to $0.78^{\circ} \mathrm{C}$ for the Indo-Pacific Run. The latter is closer to the observed value. The second noticeable difference is that the Indo-Pacific Run has a greater decadal variation in ENSO intensity than the Pacific Run. The former run can be broadly separated into two "strong variability decades" (years 10-21 and 38-52) with large warm and cold events and a "weak variability decade" (years 22-37) with weak warm and cold events. No such clear decadal differences are present in the Pacific Run. It appears that by including the Indian Ocean, the CGCM produces more realistic ENSO amplitude and stronger variability on decadal time scales.

The changes in the ENSO cycle when the Indian Ocean coupling is included may be expected, as the CGCM can now resolve
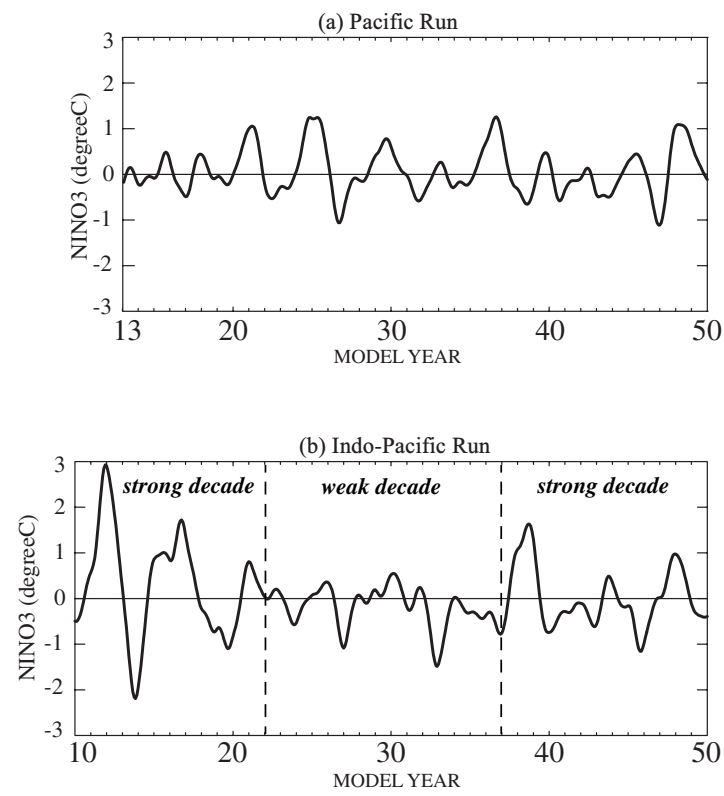

Figure 6. NINO3 SST anomalies calculated from (a) the Pacific Run and (b) the Indo-Pacific Run. These monthly values are low-pass filtered to remove variations shorter than 12 months. (From Yu et al., 2002.)

interannual variability in the Indian Ocean and its interactions with the ENSO cycle. The Indian Ocean SST variability resulting from these interactions, such as the basinwide warming/cooling and the Indian Ocean zonal/dipole mode, may feed back to affect the ENSO evolutions. In addition, since the interactive part of the tropical warm pool covers both the western Pacific Ocean and the eastern Indian Ocean in the Indo-Pacific Run, the eastern Indian Ocean part of the warm pool can respond interactively to Pacific ENSO events. This can amplify the overall feedbacks from the atmosphere during ENSO events. It was also suggested by Kug et al. (2006) that an interactive Indian Ocean can affect surface winds in the western Pacific/maritime continent, which can further affect the ENSO evolution.

$\mathrm{Yu}$ (2005) noticed that the phase-locking of ENSO to the annual cycle is enhanced and becomes more realistic in the Indo-Pacific Run compared to the Indian Ocean Run (not shown). 

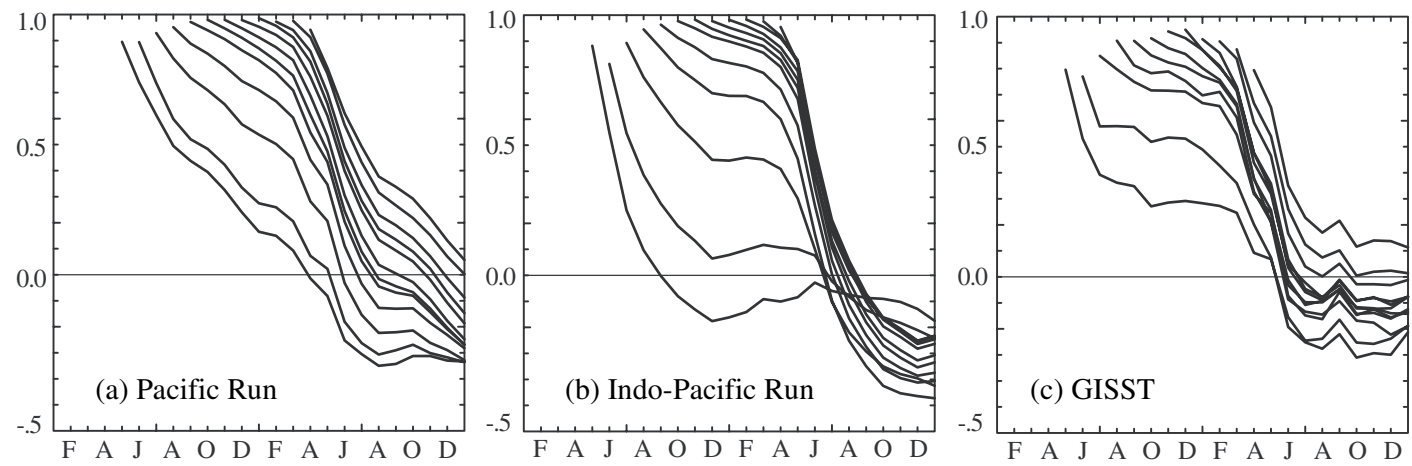

Figure 7. Lagged autocorrelation coefficients of NINO3 SST anomalies calculated from the (a) Pacific Run, (b) IndoPacific Run, and (c) GISST data. The curves are shifted to line up their one-month lag with the calendar month on the abscissa (From Yu, 2005.)

As a result of the phase-locking, the spring persistence barrier becomes more obvious in the Indo-Pacific than in the Pacific Run. The spring barrier is a well-known feature of the observed ENSO cycle. Lagged autocorrelation analyses with various ENSO indices, such as the NINO3 SST anomalies, Southern Oscillation pressure differences, and central Pacific rainfall anomalies, show sharp declines in the correlation coefficients in boreal spring (Troup, 1965; Wright, 1979; Webster and Yang, 1992; Torrence and Webster, 1998; Clarke and Gorder, 1999). Figure 7 shows the lagged correlation coefficients of the NINO3 calculated from the Pacific and Indo-Pacific runs and the observations. For the Pacific Run, Fig. 7(a) shows a more gradual decrease in the correlations and a weaker dependence of the decline on calendar months. This experiment produces a weaker spring persistence barrier than the observed [Fig. 7(c)]. Correlation coefficients in Fig. 7(c) are calculated using observed SST's from 1901 to 2000, based on the Global Sea-Ice and Sea Surface Temperature Data Set (GISST) (Rayner et al., 1996). In the Indo-Pacific Run [Fig. 7(b)], the spring barrier is stronger and more realistic, with a rapid decline in the correlations occurring in March-May for most of the 12 curves.

It is well recognized that the ENSO has a low-frequency (3-7 years) and a biennial
( $\sim 2$ years) component (Rasmusson and Carpenter, 1982; Rasmusson et al., 1990; Barnett, 1991; Gu and Philander, 1995; Jiang et al., 1995; Wang and Wang, 1996). Yu (2005) found that the biennial ENSO component is very weak in the Pacific Run, but is significantly enhanced in the Indo-Pacific Run. This is clearly shown in the power spectra of NINO3 index of Fig. 8. By analyzing the persistence barrier in the decades of strong and weak biennial and low-frequency ENSO in the Indo-Pacific Run, Yu (2005) found that the overall amplitude of ENSO is not a primary factor in determining the strength of the persistence barrier. It is the amplitude of the biennial component of ENSO that affects the barrier the most. The persistence barrier is consistently strong (weak) when biennial ENSO variability is large (small). No such clear relationship is found between the strength of the barrier and the amplitude of the low-frequency ENSO component.

Results obtained from these two basincoupling CGCM experiments (i.e. the Pacific Run and the Indo-Pacific Run) support the hypotheses that the spring persistence barrier is a result of the phase locking of ENSO (Torrence and Webster, 1998; Clarke and Gorder, 1999) and that the biennial ENSO component is crucial to the phase locking (Clarke and Gorder, 1999). Yu (2005) further suggests 
(a) Pacific Run

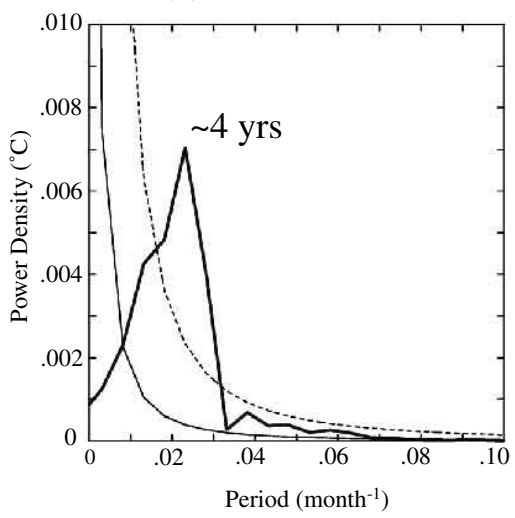

(b) Indo-Pacific Run

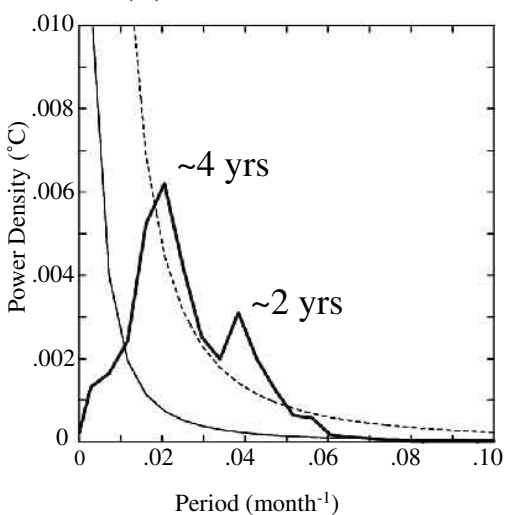

Figure 8. Power spectra of NINO3 SST anomalies calculated from the (a) Pacific Run and (b) Indo-Pacific Run. Dashed lines indicate the $95 \%$ significance level. Thin-solid lines are red-noise spectra. (From Yu, 2005.)

that the Indian Ocean coupling plays a key role in producing the biennial component of ENSO. The mechanisms for this are not yet understood, but are being studied. It is believed that the TBO in the Indian and Australian monsoons may be involved in the enhancement of the biennial ESNO component.

\section{ENSO's Interactions with the Tropospheric Biennial Oscillation (TBO)}

The TBO is a major climate variation feature of the Indian-Australian monsoon system. Years with above-normal summer rainfall tend to be followed by ones with below-normal rainfall and vice versa. The dynamics behind this phenomenon has not yet been fully understood. In work that suggests that the TBO has its own dynamics, the interactions between the monsoon and the tropical Indian and/or Pacific Oceans are emphasized to play a central role in the TBO (e.g. Nicholls, 1978; Meehl, 1987, 1993; Clarke et al., 1998; Chang and Li, 2000; Webster et al., 2002; Yu et al., 2003; Li et al., 2006). However, different theories emphasized different parts of the Indo-Pacific Oceans for the importance. Webster et al. (2002) argued that the TBO is resulted from the monsoon-ocean interaction in the Indian Ocean. The wind-driven Ekman transport provides the needed phase reversal mechanism for the biennial oscillation. Meehl (1993) believed that the TBO involves the interactions between the monsoon and the Indian Ocean and both the western and the eastern Pacific Ocean. In contrast to this view, the TBO theory of Chang and Li (2000) assigned a passive role to the eastern Pacific Ocean. Instead, they emphasized monsoon-ocean interactions in the Indian and the western Pacific Ocean for the TBO.

The basin-coupling CGCM experiments are capable of isolating the monsoon-ocean interactions in the Pacific or the Indian Ocean and are, therefore, a useful tool for examining these TBO theories. Yu et al. (2003) contrasted the Indian monsoon variability produced in all three basin-coupling CGCM experiments (i.e. Pacific, Indo-Pacific, and Indian-Ocean runs) and noticed interesting differences among them. Figure 9 shows the power spectra of the Indian summer monsoon rainfall index (IMRI; rainfall averaged over an area between $10^{\circ} \mathrm{N}$ between $30^{\circ} \mathrm{N}$, and between $65^{\circ} \mathrm{E}$ and $100^{\circ} \mathrm{E}$ ) calculated from the experiments. The figure shows that there is virtually no biennial monsoon variation in the simulation including only the Pacific Ocean coupling (i.e. the Pacific Run). 
(a) Pacific Run

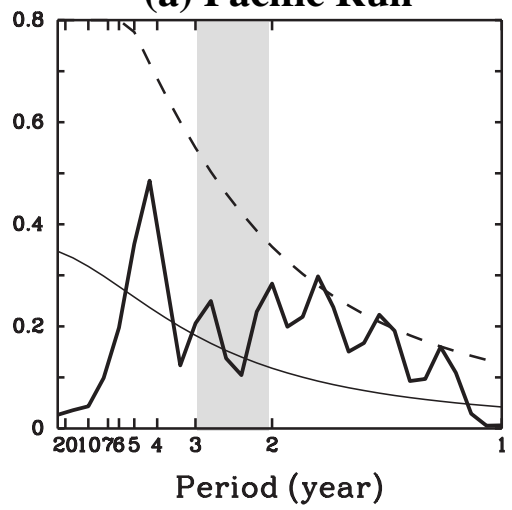

(b) Indian-Ocean Run

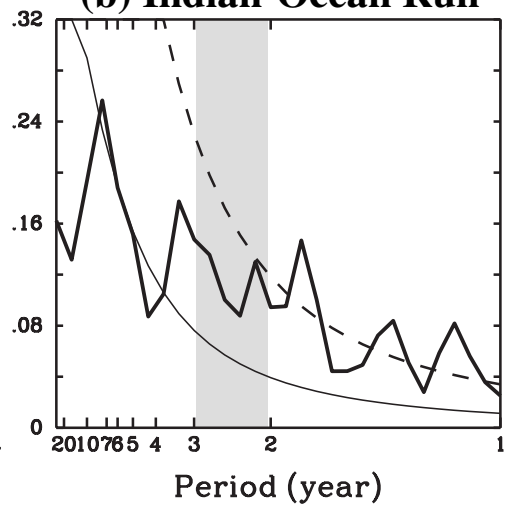

(c) Indo-Pacific Run

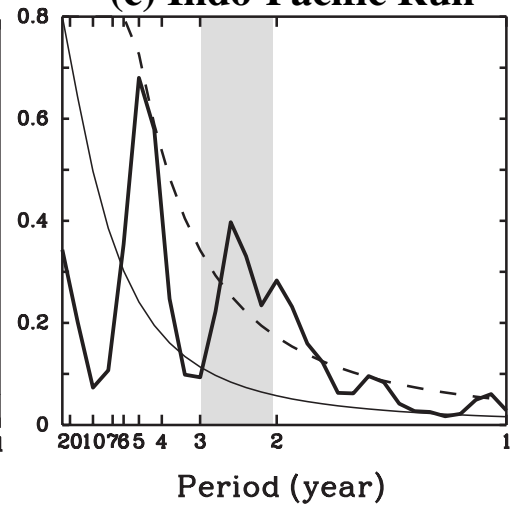

Figure 9. Power spectra of the Indian summer monsoon rainfall index calculated from the (a) Pacific Run, (b) Indian-Ocean Run, and (c) Indo-Pacific Run. The $95 \%$ significance levels are indicated by the dashed curves. The shaded area is the period for the quasi-biennial oscillation.

With only the Indian Ocean coupling, the biennial peak is enhanced but is not strong enough to pass the statistical significance level (i.e. the Indian Ocean Run). A statistically significant biennial peak shows up only in the CGCM simulation that includes both the Pacific and Indian Ocean couplings (Indo-Pacific Run). These results suggest that the monsoon-ocean interaction in the Indian Ocean is able to produce weak biennial monsoon variability, and the biennial variability is further enhanced when the interactions between the Indian and the Pacific Ocean are included. The interactions and feedbacks between TBO and the biennial ENSO component are probably responsible for this enhancement.

An important aspect of the TBO is that the biennial tendency in the Indian summer monsoon is related to the biennial tendency in the Australian summer monsoon (Meehl, 1987, 1993). A strong (weak) Indian summer monsoon is often followed by a strong (weak) Australian summer monsoon. The anomalies then reverse sign as they return to the northern hemisphere and lead to a weak (strong) Indian monsoon during the northern summer of the following year. The in-phase transition from Indian summer monsoon to Australian summer monsoon and the out-of- phase transition from Australian summer monsoon to Indian summer monsoon of the next year are two key features of the TBO.

$\mathrm{Yu}$ et al. (2003) examined the role of the Indian and Pacific Oceans in these two monsoon transitions of the TBO. They noticed that the in-phase monsoon transition was produced more often in the CGCM experiments that included the Pacific Ocean coupling (the Pacific and Indo-Pacific Runs), while the out-of-phase transition was produced more often in the experiments that included the Indian Ocean coupling (the Indian Ocean and Indo-Pacific Runs). These results are demonstrated in Fig. 10, which displays the lagged correlation coefficients between the simulated monthly IMRI and Australian monsoon rainfall index (AMRI; rainfall averaged over an area between $100^{\circ} \mathrm{E}-$ $150^{\circ} \mathrm{E}$ and $20 \mathrm{~S}-5^{\circ} \mathrm{N}$ ) anomalies. The figure shows that both the observations and the IndoPacific CGCM Run produce two large correlation coefficients: a positive coefficient with the IMRI leads the AMRI by about two seasons, and a negative coefficient with the AMRI leads the IMRI by about two seasons. The large positive correlation represents the in-phase transition from Indian to Australian summer monsoons. 
(a) CMAP Observation

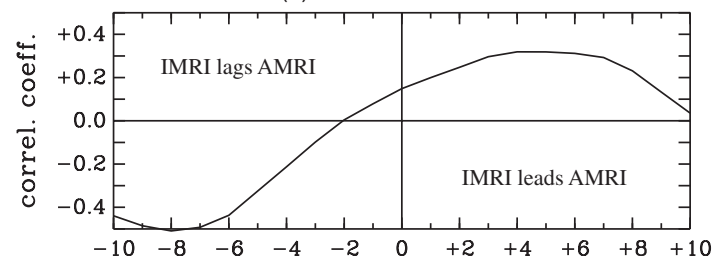

(b) Indo-Pacific Run

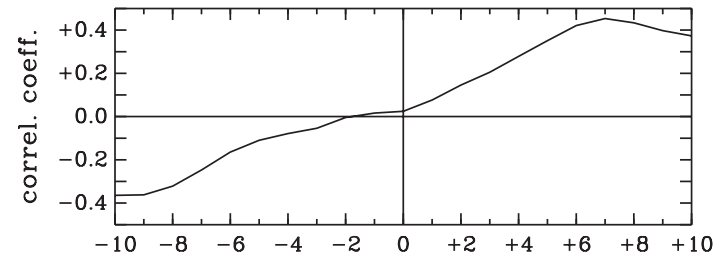

(c) Pacific Run

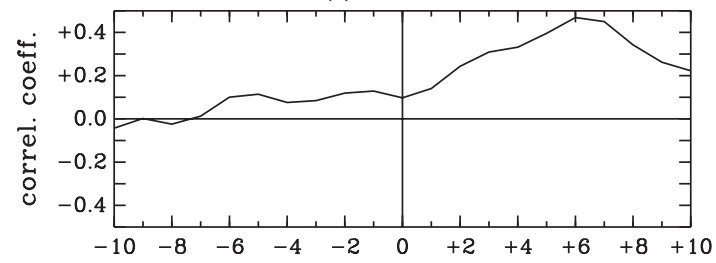

(d) Indian-Ocean Run

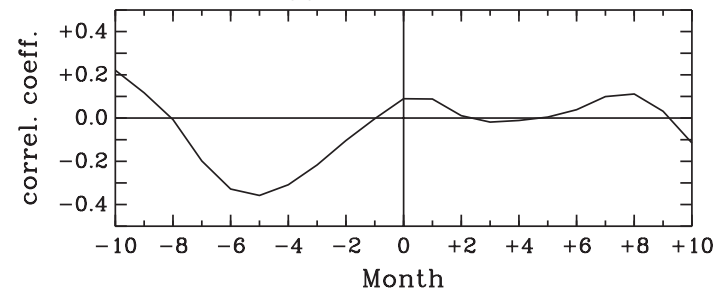

Figure 10. Time-lagged correlation coefficients between the monthly IMRI and AMRI calculated from the (a) CMAP observation, (b) Indo-Pacific Run, (c) Pacific Run, and (d) Indian Ocean Run. (From Yu et al., 2003.)

The negative one represents the out-of-phase transition from Australian to Asian summer monsoons. The CGCM produces only the large positive correlations (i.e. the in-phase transition) in the Pacific Run, and produces only the large negative correlation (i.e. the out-ofphase transition) in the Indian Ocean Run. These results suggest that the Pacific Ocean coupling is crucial to the in-phase transition from the Indian summer monsoon to the Australian summer monsoon. The Indian Ocean coupling is crucial to the out-of-phase transition from the Australian summer monsoon back to the Indian summer monsoon.

By analyzing SST evolutions during the monsoon transitions, $\mathrm{Yu}$ et al. (2003) noticed that the Indian and Pacific Oceans showed different and interesting relationships with the inphase and out-of-phase monsoon transitions. Figure 11 is constructed to summarize these different SST evolutions and their relationships with the monsoon transitions. In this figure, the evolutions of SST anomalies in the central Indian Ocean $\left(20^{\circ} \mathrm{S}-20^{\circ} \mathrm{N} ; 40^{\circ} \mathrm{E}-80^{\circ} \mathrm{E}\right)$ and in the central Pacific Ocean $\left(10^{\circ} \mathrm{S}-10^{\circ} \mathrm{N} ; 150^{\circ} \mathrm{E}-\right.$ $\left.170^{\circ} \mathrm{W}\right)$ are composited for the in-phase and out-of-phase monsoon transitions. The corresponding IMRI and AMRI values composited during those seasons are also shown in the figure. Figure 11(a) shows that after a strong (weak) Indian summer monsoon occurs, SST anomalies change sign in the Indian Ocean. SST anomalies are small throughout this in-phase monsoon transition. During the same period, SST anomalies in the Pacific Ocean are large and contribute to the in-phase monsoon transition. Figure 11(b) shows that, after changing sign in the Indian summer monsoon season, Indian Ocean SST anomalies continue to grow and reach large amplitudes during the out-ofphase monsoon transition. During this transition period, the Pacific SST anomalies change sign. Therefore, SST anomalies in the Pacific are small. The large Indian Ocean SST anomalies contribute to the out-of-phase monsoon transition from a strong (weak) Australian summer monsoon to a weak (strong) Indian summer monsoon.

The different evolutions of the Indian and Pacific Ocean SST anomalies are the key that reveals the different roles of these two oceans in the transition phases of the TBO. Figure 12 illustrates how the different monsoon-ocean interactions lead to the TBO. For the sake of discussion, the process begins with warm Indian Ocean SST anomalies and cold (La Niña-type) Pacific SST anomalies, an SST 
(a) In-Phase Transition

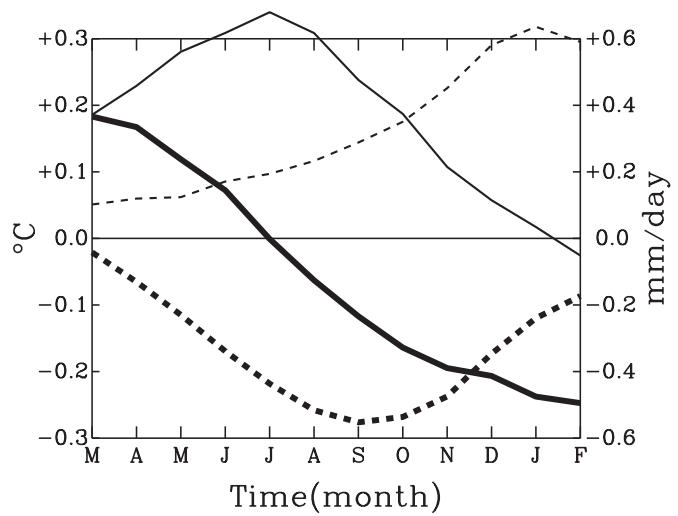

(b) Out-of-Phase Transition

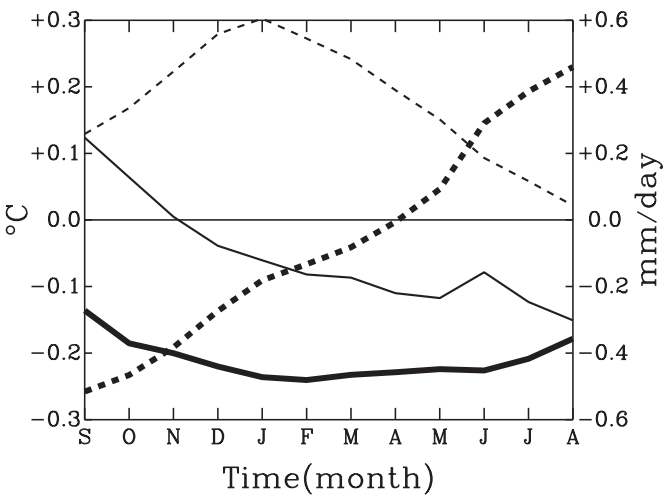

Figure 11. Temporal evolutions of the IMRI (thin-solid), AMRI (thin-dashed), central Pacific SST (Pac-SST; thick-dashed), and central Indian Ocean SST (Indo-SST; thick-solid) during the (a) in-phase monsoon transition and (b) out-of-phase monsoon transition. All values are composited from the Indo-Pacific Run.

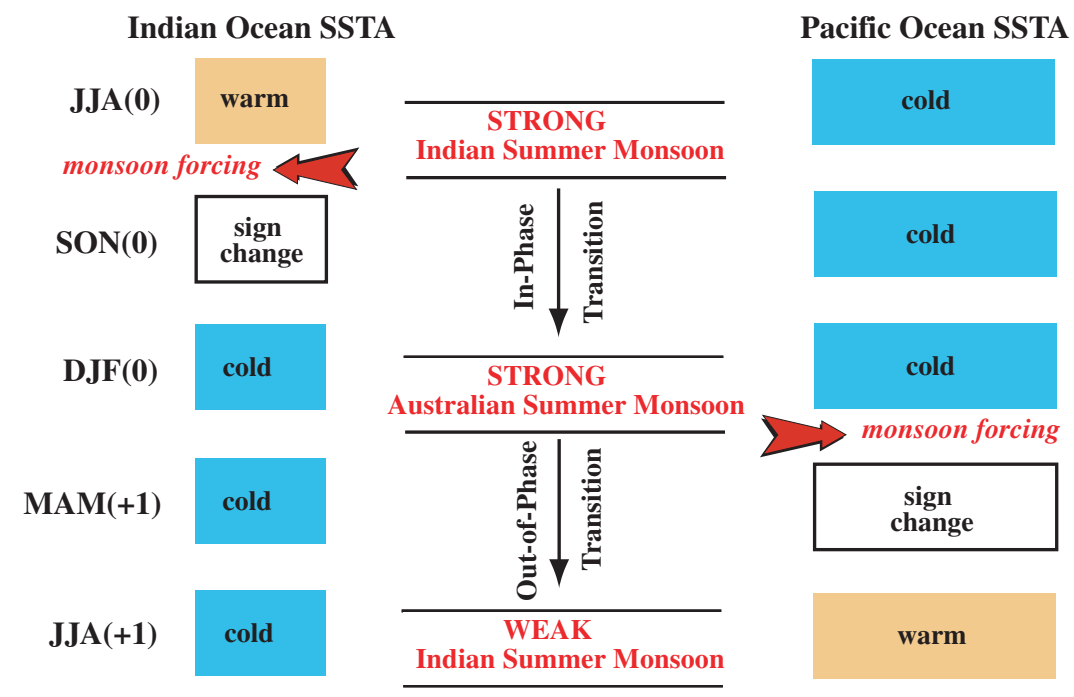

Figure 12. Schematic illustrating the relationship between the Indian-Australian summer monsoons and the IndoPacific Ocean SST anomalies (SSTA) during the TBO.

anomaly pattern typically associated with a strong Indian monsoon in June-July-August (JJA, Year 0) (Lau and Yang, 1996). The strong monsoon winds force the Indian Ocean SST anomalies to reverse sign. The Indian Ocean SST anomalies in September-OctoberNovember (SON, Year 0) are, therefore, in transition and have small amplitudes. During the same period, the large cold Pacific SST anomalies persist and dominate the in-phase transition to a strong Australian summer monsoon in December-January-February (DJF, Year 0). This explains why the Pacific Ocean coupling is more important to the in-phase transition from the Indian summer monsoon to the Australian summer monsoon. The strong Australian summer monsoon winds then force the Pacific SST anomalies to change sign and 
to have small amplitudes in March-April-May (MAM, next year; +1). During this period, cold SST anomalies have been established in the Indian Ocean and have grown to large amplitudes. These cold Indian Ocean SST anomalies then dominate the out-of-phase transition and lead to a weak Asian summer monsoon in JJA of the next year. This explains why the Indian Ocean coupling is needed for the CGCM to produce the out-of-phase monsoon transition. The specific air-sea coupling processes that are involved in these monsoon-ocean interaction should be similar to the windevaporation/entrainment and cloud-radiating feedback processes discussed by Wang et al. (2003). They showed that these processes allow the remote forcing of ENSO in the Indo-Pacific warm pool to be amplified and maintained from the developing summer to the decaying summer of an ENSO event, to contribute to the formation of the TBO.

$\mathrm{Yu}$ et al. (2003) concluded that the Indian summer monsoon has a stronger impact on the Indian Ocean than on the Pacific Ocean, and that the Australian summer monsoon has a stronger impact on the Pacific Ocean than on the Indian Ocean. These seasonally dependent monsoon influences allow the Pacific and Indian Oceans to have different feedbacks during the in-phase and out-of-phase monsoon transitions, and thus lead to the TBO.

\section{ENSO's Interactions with Indian Ocean SST Variability}

The recent interest in the observed eastwest contrast pattern in Indian Ocean SST anomalies has prompted the suggestion that the Indian Ocean has its own unstable coupled atmosphere-ocean mode similar to ENSO (e.g. Saji et al., 1999; Webster et al., 1999). This interannual SST variability is often referred to as the Indian Ocean zonal mode (IOZM) or Indian Ocean dipole. The IOZM is characterized by opposite polarities of SST anomalies between the western and eastern parts of the equatorial Indian Ocean, and is always accompanied with zonal wind anomalies in the central Indian Ocean. The strong wind-SST coupling associated with the IOZM has been used to argue for the similarity of the phenomenon to the delayed oscillator of ENSO (Webster et al., 1999). The fact that the temporal correlation between the observed IOZM and ENSO events is not strong, and that several significant IOZM events have occurred in the absence of large ENSO events, have led to the suggestion that the IOZM is independent of ENSO (Saji et al., 1999). On the other hand, there are suggestions that the IOZM is not an independent phenomenon, but is forced by ENSO through changes in surface heat flux or Indian Ocean circulation (e.g. Klein et al., 1999; Chambers et al., 1999; Murtugudde and Busalacchi, 1999; Venzke et al., 2000; Schiller et al., 2000; Huang and Kinter, 2002; Xie et al., 2002). It has also been suggested that the IOZM is a weak natural coupled mode of the Indian Ocean that can be amplified by ENSO during a particular season (e.g. Gualdi et al., 2003; Annamalai et al., 2003). The IOZM is also suggested to be a natural part of the Indian summer monsoon and the TBO (e.g. Meehl and Arblaster, 2002; Loschnigg et al., 2003, Li et al., 2006). The IOZM is argued to arise from the ocean-atmosphere interactions within the Indian Ocean with links to the Pacific involved with the TBO.

$\mathrm{Yu}$ and Lau (2004) examined the intrinsic and forced SST variability in the Indian Ocean by contrasting the Indian ocean SST variability between the Indo-Pacific and Indian Ocean Runs. The former run includes ENSO influences, while the latter one excludes the influences. The M-SSA was applied to the interannual anomalies of Indian Ocean SST to extract leading oscillatory modes from the simulations. One major advantage of the M-SSA is that it easily identifies oscillatory behavior, even if it is not purely sinusoidal (Robertson et al., 1995). In the M-SSA, an oscillatory mode appears as 
a pair of M-SSA modes that have similar eigenvalues, similar sinusoidal principal components in quadrature with each other, and similar eigenvector structures.

In the Indo-Pacific Run, an oscillatory mode of the Indian Ocean SST variability was found with the M-SSA (not shown). The mode comprises two patterns that can be identified with the IOZM and a basinwide warming/cooling mode respectively. To link the oscillatory mode to the interannual SST variability in the Pacific Ocean, we calculated the time-lag correlation coefficients between the principal component of the leading M-SSA mode and SST anomalies in the entire Indo-Pacific Ocean. Figure 13 shows that the correlation is characterized by an IOZM pattern in the Indian Ocean and an ENSO pattern in the Pacific. The time sequence simulated in the Indo-Pacific Run appears close to the sequence observed during the 1997-98 ENSO event, although discrepancies exist. One discrepancy is that, in the Indo-Pacific Run, ENSO peaks earlier than does the IOZM. The

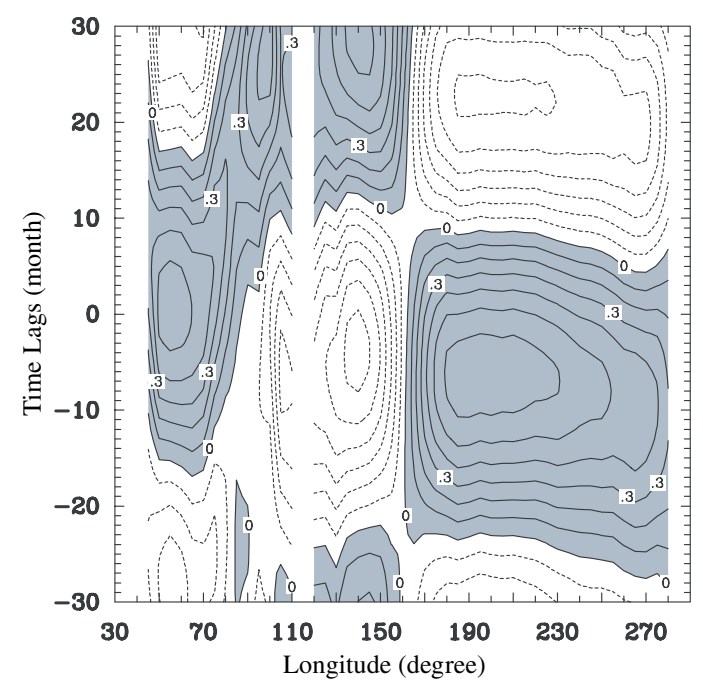

Figure 13. Time-lag correlation coefficients between the principal component of the leading M-SSA mode of the interannual Indian Ocean SST variability and the low-pass filtered SST anomalies in the Indo-Pacific Run. Values are averaged between $4^{\circ} \mathrm{S}$ and $4^{\circ} \mathrm{N}$. Contour intervals are 0.1. Positive values are shaded. (From Yu and Lau, 2004.)
ENSO pattern peaks about 3.5 months before the IOZM peaks. This discrepancy may be due to the fact that the model ENSO tends to peak in early fall, rather than in winter as observed (Yu and Mechoso, 2001). The close connection between the IOZM and ENSO in the correlation analyses suggests that the IOZM-like oscillatory mode in the Indo-Pacific Run is related to ENSO. The correlation between the time series of the NINO3 index and the IOZM index from the Indo-Pacific Run is also examined. Following Saji et al. (1999), the IOZM index is defined as the SST anomaly difference between the western Indian Ocean $\left(50^{\circ} \mathrm{E}-70^{\circ} \mathrm{E}\right.$ and $\left.10^{\circ} \mathrm{S}-10^{\circ} \mathrm{N}\right)$ and the eastern Indian Ocean $\left(90^{\circ} \mathrm{E}-110^{\circ} \mathrm{E}\right.$ and $\left.10^{\circ} \mathrm{S}-0^{\circ}\right)$. It is found that major IOZM and ENSO events coincide with each other during the simulation (not shown), although the simultaneous correlation coefficient between them is only 0.5 .

No oscillatory mode can be found in the Indian Ocean when the ENSO influence is excluded in the Indian Ocean Run. However, IOZM-like features can still be found in the leading variability modes of the Indian Ocean SST. Examinations of these IOZM-like features in the Indian Ocean Run reveal similar oceanatmosphere coupling associated with enhanced and weakened Indian summer monsoon circulations, as in the Indo-Pacific Run. Our modeling results indicate that IOZM-like features can occur even in the absence of large ENSO events in the Pacific. However, the oscillatory feature of the IOZM is forced by ENSO. ENSO acts as a strong pacemaker to the IOZM. The IOZM may be considered a coupled mode that is weakly damped and cannot be self-sustained when lacking external forcing, such as ENSO and the monsoon (Li et al., 2003).

\section{Conclusions}

Climate changes and variations have strong impacts on human society, and are of common concern to people across national and regional 
boundaries. In the Indo-Pacific sector, ENSO and the monsoon are two of the most important climate features. These two features occur on opposite sides of the Indo-Pacific basin but have strong interactions with each other. A better understanding of their complex interactions and feedbacks is crucial for successful forecasts of ENSO and monsoon variability. This article reports a unique modeling effort toward that goal. By turning on and off the atmosphereocean coupling in various regions of the IndoPacific Ocean, the interactions between ENSO and the Indian Ocean and monsoon can be isolated in different CGCM experiments to study the ENSO-monsoon interaction and the ENSOIndian Ocean interactions individually.

The results obtained from this series of basin-coupling CGCM experiments suggest that the Indian Ocean-monsoon system plays an active role in affecting the amplitude, frequency, and evolution of ENSO and in modulating their decadal variations. The Indian Oceanmonsoon system should be considered a crucial part of the ENSO dynamics. It is known that the Indian Ocean has been experiencing a gradual but significant warming trend in the past few decades (Nitta and Yamada, 1989; Terray, 1994; Wang, 1995). This trend may change the importance of the Indian Ocean to ENSO, and may be an additional reason for the decadal ENSO variability. In particular, the modeling results reported here indicate that the Indian Ocean-monsoon system is crucial to the selection of the dominant frequency of ENSO. An active Indian Ocean may favor a shorter period of ENSO, i.e. the biennial ENSO component. For the low-frequency ENSO component, influence from the Indian Ocean may be less important. The interactions between the Pacific and the Indian Ocean may be different between the decades that have strong biennial ENSO and the decades that have strong lowfrequency ENSO. Much more can be learned about the decadal variability of ENSO by looking into the ENSO-Indian Ocean-monsoon interactions from the perspective of biennial and low-frequency components of ENSO. The basincoupling modeling strategy pioneered in these CGCM experiments will be a useful and effective tool for the investigations.

\section{Acknowledgements}

Support from NOAA (NA03OAR4310061), NSF (ATM-0638432), and NASA (NAG5-13248 and NNX06AF49H) is acknowledged. Model integrations and analyses were performed at the San Diego Supercomputer Center (SDSC) and the University of California Irvine's Earth System Modeling Facility, which is funded by the National Science Foundation (ATM-0321380).

[Received 15 December 2005; Revised 9 May 2007; Accepted 4 June 2007.]

\section{References}

Annamalai, H. R., M. J. Potemra, S. P. Xie, P. Liu, and B. Wang, 2003: Couple dynamics over the Indian Ocean: spring initialization of the zonal mode. Deep-Sea Research II, 50, 2305-2330.

Arakawa, A., and W. H. Schubert, 1974: Interaction of a cumulus cloud ensemble with the large-scale environment, Part I. J. Atmos. Sci., 31, 674-701.

Barnet, T. P., 1984: Interaction of the monsoon and Pacific trade wind system at interannual time scales. Mon. Wea. Rev., 112, 2380-2387.

Barnet, T. P., 1991: The interaction of multiple time scales in the tropical climate system. J. Climate, 4, 269-285.

Battisti, D. S., and A. C. Hirst, 1989: Interannual variability in the tropical atmosphereocean system: Influence of the basic state, ocean geometry, and nonlinearity. J. Atmos. Sci., 46, 1687-1712.

Bjerknes, J., 1969: Atmospheric teleconnections from the equatorial Pacific. Mon. Wea. Rew., 97, 163-172.

Bryan, K., 1969: A numerical method for the study of the circulation of the world ocean. J. Comp. Phys., 4, 347-376.

Cane, M. A., and S. E. Zebiak, 1985: A theory for El Niño and Southern Oscillation. Science, 288, 1085-1087. 
Cane, M. A., S. E. Zebiak, and S. C. Dolan, 1986: Experimental forecasts of EL Niño. Nature, 321, 827-832.

Cane, M. A., and S. E. Zebiak, 1987: Model El NiñoSouthern Oscillation. Mon. Wea. Rev., 10, 22622278 .

Chambers, D. P., B. D. Tapley, and R. H. Stewart, 1999: Anomalous warming in the Indian Ocean coincident with El Niño. J. Geophys. Res., 104, 3035-3047.

Chang, C.-P., and T. Li, 2000: A theory for the tropical tropospheric biennial oscillation. J. Atmos. Sci., 57, 2209-2224.

Chiang, J. C. H., and A. H. Sobel, 2002: Tropical tropospheric temperature variations caused by ENSO and their influence on the remote tropical climate. J. Climate, 15, 2616-2631.

Clarke, A. J., X. Liu, and S. V. Gorder, 1998: Dynamics of the biennial oscillation in the equatorial Indian and far western Pacific Oceans. J. Climate, 11, 987-1001.

Clarke, A. J., and S. Van Gorder, 1999: The connection between the boreal spring Southern Oscillation persistence barrier and biennial variability. J. Climate, 12, 610-620.

Cox, M. D., 1984: A primitive equation threedimensional model of the ocean. GFDL Ocean Group Tech. Rep. No. 1.

Deardorff, J. W., 1972: Parameterization of the planetary boundary layer for use in general circulation models. Mon. Wea. Rev., 100, 93-106.

Delecluse, P., M. K. Davey, Y. Kitamura, S. G. H. Philander, M. Suarez, and L. Bengtsson, 1998: Coupled general circulation modeling of the tropical Pacific, J. Geophys. Res., 103, 1435714374, 10.1029/97JC02546.

Fasullo, J., 2004: Biennial characteristics of Indian monsoon rainfall. J. Climate, 17, 2972-2982.

Fedorov, A. V. and S. G. H. Philander, 2000: Is El Niño changing? Science, 288, 1997-2002.

Godfrey, J. S., 1996: The effects of the Indonesian throughflow on ocean circulation and heat exchange with the atmosphere: A review. J. Geophys. Res., 101, 12217-12237.

Gu, D., and S. G. H. Philander, 1995: Secular changes of annual and interannual variability in the tropics during the past centry. J. Climate, $\mathbf{8}$, 864-876.

Gualdi, S., E. Guilyardi, A. Navarra, S. Masina, and P. Delecluse, 2003: The interannual variability in the tropical Indian Ocean. Clim. Dyn., 20, $567-582$.
Harshvardhan, D. A. Randall, and T. G. Corsetti, 1987: A fast radiation parameterization for general circulation models. J. Geophys. Res., 92, 1009-1016.

Hirst, A. C., and J. S. Godfrey, 1993: The role of Indonesian throughflow in a global ocean GCM. J. Phys. Oceanog., 23, 1057-1086.

Huang, B., and J. L. Kinter, 2002: The interannual variability in the tropical Indian Ocean and its relations to El Niño-Southern Oscillation. J. Geophys. Res., 107, 3199 (doi:10.1029/2001J C001278).

Jiang, N., J. D. Neelin, and M. Ghil, 1995: Quasiquadrennial and quasi-biennial variability in the equatorial Pacific. Clim. Dyn., 12, 101-112.

Jin, F.-F., 1997: An equatorial recharge paradigm for ENSO, I. Conceptual model. J. Atmos. Sci., 54, 811-829.

Katayama, A., 1972: A simplified scheme for computing radiative transfer in the troposphere. Numerical Simulation of Weather and Climate Tech. Rep. 6, 77 pp. (Available from Department of Atmospheric Sciences, University of California, Los Angeles, CA 90024, USA.)

Keppenne, C. L., and M. Ghil, 1992: Adaptive spectral analysis and prediction of the southern oscillation index. J. Geophys. Res., 97, 20449 20454.

Kiladis, G. N., and H. van Loon, 1988: The Southern Oscillation. Part VII: Meteorological anomalies over the Indian and Pacific sectors associated with the extremes of the oscillation. Mon. Wea. Rev., 116, 120-136.

Kim, Y.-J. and A. Arakawa, 1995: Improvement of orographic gravity-wave parameterization using a mesoscale gravity-wave model. J. Atmos. Sci., 52, 1875-1902.

Klein, S. A., B. J. Soden, and N.-C. Lau, 1999: Remote sea surface temperature variations during ENSO: Evidence for a tropical atmospheric bridge. J. Climate, 12, 917-932.

Kug, J.-S., and I.-S. Kang, 2005: Interactive feedback between ENSO and the Indian Ocean., J. Climate; Accepted.

Kug, J.-S., T. Li, S.-I. An, I.-S. Kang, J.-J. Luo, S. Masson, and T. Yamagata, 2006: Role of the ENSO-Indian Ocean Coupling on ENSO variability in a coupled GCM. Geophys. Res. Lett., 33, doi:10.1029/2005GL024916.

Latif, M., and Coauthors, 2001: The El Niño simulation intercomparison project. Clim. Dyn., 18 $255-276$. 
Lau, N.-C., and M. J. Nath, 1996: The role of the "atmospheric bridge" in linking tropical Pacific ENSO events to extratropical SST anomalies, J. Climate, 9, 2036-2057.

Lau, N.-C., and M. J. Nath, 2006: ENSO modulation of the interannual and intraseasonal variability of the East Asian monsoon: A model study. J. Climate, 19, 4508-4530.

Lau, K. M., and S. Yang, 1996: The Asian monsoon and predictability of the tropical oceanatmosphere system. Quart. J. Roy. Meteor. Soc., 122, 945-957.

Lee, T., I. Fukumori, D. Menemenlis, Z. Xing, and L. L. Fu, 2002: Effects of the Indonesian throughflow on the Pacific and Indian Oceans. $J$. Phys. Oceangr., 32, 1404-1429.

Li, T., 1997: Phase transition of the El NiñoSouthern Oscillation: A stationary SST mode. J. Atmos. Sci., 54, 2872-2887.

Li, T., B. Wang, C.-P. Chang, and Y. Zhang, 2003: A theory for the Indian Ocean dipole-zonal mode. J. Atmos. Sci., 60, 2119-2135.

Li, T., P. Liu, X. Fu, B. Wang, and G. A. Meehl, 2006: Tempo-spatial structures and mechanisms of the tropospheric biennial oscillation in the Indo-Pacific warm ocean regions. J. Climate, 19, 3070-3087.

Liu, W. T., W. Tang, and H. Hu, 1998: Spaceborne sensors observe El Niño's effects on ocean and atmosphere in North Pacific. EOS, 79, No. 21.

Loschnigg, J., G. A. Meehl, P. J. Webster, J. M. Arblaster, and G. P. Compo, 2003: The Asian monsoon, the tropospheric biennial oscillation and the Indian Ocean dipole in the NCAR CSM. J. Climate, 16, 2138-2158.

Mechoso, C. R., J.-Y. Yu, and A. Arakawa, 2000: A coupled GCM pilgrimage: From climate catastrophe to ENSO simulations. Book chapter in General Circulation Model Development: Past, Present, and Future., D. A. Randall (eds.), Academic, $807 \mathrm{pp}$.

Meehl, G. A., 1987: The annual cycle and interannual variability in the tropical Indian and Pacific Ocean regions. Mon. Wea. Rev., 115, $27-50$.

Meehl, G. A., 1993: A coupled air-sea biennial mechanism in the tropical Indian and Pacific regions: role of oceans. J. Climate, 6, 31-41.

Meehl, G. A., and J. M. Arblaster, 2002: The tropospheric biennial oscillation and Asian-Australian monsoon rainfall. J. Climate, 15, 722-744.

Mellor, G. L., and T. Yamada, 1982: Development of a turbulence closure model for geophysical fluid problems. Rev. Geophys. Space Phys., 20, 851-875.

Mooley, D. A., and B. Parthasarathy, 1984: Fluctuations in all-India summer monsoon rainfall during 1871-1978. Climate Change, 6, 287-301.

Murtugudde, R., A. Busalacchi, and J. Beauchamp, 1998: Seasonal-to-interannual effects of the Indonesian throughflow on the Indo-Pacific Basin. J. Geophys. Res., 103, 21245-21441.

Murtugudde, R., and A. J. Busalacchi, 1999: Interannual variability of the dynamics and thermodynamics of the tropical Indian Ocean. J. Climate, 12, 2300-2326.

Murtugudde, R., J. P. McCreary, and A. J. Busalacchi, 2000: Oceanic processes associated with anomalous events in the Indian Ocean with relevance to 1997-1998. J. Geophys. Res., 105, 32953306.

Neelin, J. D., C. Chou, and H. Su, 2003: Tropical drought regions in global warming and El Niño teleconnections. Geophys. Res. Lett., 30, 2275, doi:10.1029/2003GL018625.

Nicholls, N., 1978: Air-sea interaction and the quasi-biennial oscillation. Mon. Wea. Rev., 106 , 1505-1508.

Nitta, T., and S. Yamada, 1989: Recent warming of tropical sea surface temperature and its relationship to the northern hemisphere circulation. J. Meteor. Soc. Japan, 67, 375-383.

Pacanowski, R. C., K. W. Dixon, and A. Rosati, 1991: The GFDL Modular Ocean Model user guide. Tech. Rep. 2, NOAA/GFDL, Princeton, NJ, 75 pp. (Available from GFDL/NOAA, Princeton University, Princeton, NJ 08540, USA.)

Rasmusson, E. M., and T. H. Carpenter, 1982: Variations in tropical sea surface temperature and surface wind fields associated with the Southern Oscillation/El Niño. Mon. Wea. Rev., 110, 354-384.

Rasmusson, E. M., X. Wang, and C. F. Ropelewski, 1990: The biennial component of ENSO variability. J. Mar. Syst., 1, 71-96.

Rayner, N. A., E. B. Horton, D. E. Parker, C. K. Folland, and R. B. Hackett, 1996: Version 2.2 of the Global Sea-Ice and Sea Surface Temperature Data Set, 1903-1994 (Clim. Res. Tech. Notes. 74, UK Meteorological Office, Bracknell).

Robertson, A. W., C.-C. Ma, C. R. Mechoso, and M. Ghil, 1995: Simulation of the tropical Pacific climate with a coupled ocean-atmosphere general circulation model. Part I: The seasonal cycle. J. Climate, 8, 1178-1198. 
Ropelewski, C. F., M. S. Halpert, and X. Wang, 1992: Observed tropospheric biennial variability and its relationship to the Southern Oscillation. J. Climate, 5, 594-614.

Saji N. H., B. N. Goswami, P. N. Vinayachandran and T. Yamagata, 1999: A dipole mode in the tropical Indian Ocean, Nature, 401, 360-363.

Schiller, A., J. S. Godfrey, P. C. McIntosh, G. Meyers, and R. Fielder, 2000. Interannual dynamics and thermodynamics of the IndoPacific Oceans. J. Phys. Oceanog., 30, 987-1012.

Schopf, P. S., and M. J. Suarez, 1988: Vacillations in a coupled ocean-atmosphere model. J. Atmos. Sci., 45, 549-566.

Shukla, J., and D. A. Paolino, 1983: The Southern Oscillation and long-range forecasting of the summer monsoon rainfall over India. Mon. Wea. Rev., 111, 1830-1837.

Suarez, M. J., A. Arakawa and D. A. Randall, 1983 The parameterization of the planetary boundary layer in the UCLA general circulation model: formulation and results. Mon. Wea. Rev., 111, 2224-2243.

Terray, P., 1994: An evaluation of climatological data in the Indian Ocean area. J. Meteor. Soc. Japan, 72, 359-386.

Terray, P., and S. Dominiak, 2005: Indian Ocean sea surface temperature and El Niño-Southern Oscillation: A new perspective. J. Climate, 18, 1351-1368.

Torrence, C., and P. J. Webster, 1998: The annual cycle of persistence in the El Niño/Southern Oscillation. Quart. J. Roy. Meteor. Soc., 124, 1985-2004.

Troup, A. J., 1965: The southern oscillation. Quart. J. Roy. Meteor. Soc., 91, 490-506.

Venzke, S., M. Latif, and A. Vilwock, 2000: The coupled GCM ECHO-2, II, Indian Ocean response. J. Climate, 13, 1371-1383.

Wainer, I., and P. J. Webster, 1996: MonsoonENSO interaction using a simple coupled oceanatmosphere model. J. Geophys. Res., 101, 25599-25614.

Wang, B., 1995: Interdecadal changes in El Niño onset in the last four decades. J. Climate, 8, 267285.

Wang, B., and Y. Wang, 1996: Temporal structure of the southern oscillation as revealed by waveform and wavelet analysis. J. Climate, 9, 1586-1598.

Wang, B., R. Wu, and X. Fu, 2000: Pacific-East Asian teleconnection: How does ENSO affect East Asian climate? J. Climate, 13, 1517-1536.

Wang, B., R. Wu, and T. Li, 2003: Atmospherewarm ocean interaction and its impact on
Asian-Australian monsoon variation. J. Climate, 16, 1195-1211.

Webster, P. J., and S. Yang, 1992: Monsoon and ENSO: selectively interactive systems. Quart. J. Roy. Meteor. Soc., 118, 877-925.

Webster, P. J., S. Yang, I. Wainer, and S. Dixit, 1992: Processes involved in monsoon variability. In Physical Processes in Atmospheric Models, D. R. Sikka and S. S. Singh (eds.), Wiley Eastern, New Delhi, pp. 492-500.

Webster, P. J., V. O. Magana, T. N. Palmer, J. Shukla, R. A. Tomas, M. Yanai, and T. Yasunari, 1998: Monsoons: Processes, predictability, and the prospects for prediction. J. Geophys. Res., 103, 14451-14510.

Webster, P. J., A. Moore, J. Loschnigg and M. Leban: 1999: Coupled ocean-atmosphere dynamics in the Indian Ocean during 1997-98, Nature, 40, 356-360.

Webster, P. J., C. Clark, G. Cherikova, J. Fasullo, W. Han, J. Loschnigg, and K. Sahami, 2002: The monsoon as a self-regulating coupled ocean-atmosphere system. Meteorology at the Millennium, International Geophysical Series, Vol. 83, Academic, pp. 198-219.

Wright, P. B., 1979: Persistence of rainfall anomalies in the central Pacific. Nature, 277, 371-374.

Wu, R., and B. P. Kirtman, 2004: Impacts of the Indian Ocean on the Indian summer monsoonENSO relationship. J. Climate, 17, 3037-3054.

Wyrtki, K., 1975: El Niño - the dynamic response of the equatorial Pacific Ocean to atmospheric forcing. J. Phys. Oceanog., 5, 572-584.

Xie, S. P., H. Annamalai, F. A. Schott, J. P. McCreary, 2002: Structure and mechanisms of south Indian Ocean climate variability. J. Climate, 15, 867-878.

Yasunari, T., 1990: Impact of Indian monsoon on the coupled atmosphere-ocean system in the tropical Pacific. Meteor. Atmos. Phys., 44, 29-41.

Yu, J.-Y., and C. R. Mechoso, 1999: Links between annual variations of Peruvian stratocumulus clouds and of SSTs in the eastern equatorial Pacific. J. Climate, 12, 3305-3318.

Yu, J.-Y., W. T. Liu, and C. R. Mechoso, 2000: The SST anomaly dipole in the northern subtropical Pacific and its relationship with ENSO. Geophys. Res. Lett., 27, 1931-1934.

Yu, J.-Y., and C. R. Mechoso, 2001: A coupled atmosphere-ocean GCM study of the ENSO cycle. J. Climate, 14, 2329-2350.

Yu, J.-Y., C. R. Mechoso, J. C. McWilliams, and A. Arakawa, 2002: Impacts of the Indian Ocean 
on the ENSO cycle. Geophys. Res. Lett., 29, 46.1-46.4.

Yu, J.-Y., S.-P. Weng, and J. D. Farrara, 2003: Ocean roles in the TBO transitions of the IndianAustralian monsoon system. J. Climate, 16, 3072-3080.

Yu, J.-Y., and K. M. Lau, 2004: Contrasting Indian Ocean SST variability with and without ENSO influence: A coupled atmosphere-ocean GCM study. Meteor. Atmos. Phys., DOI: 10.1007/00703-004-0094-7.

Yu, J.-Y., 2005: Enhancement of ENSO's persistence barrier by biennial variability in a coupled atmosphere-ocean general circulation model. Geophys. Res. Lett., 32, L13707, doi:10.1029/ 2005 GL023406.

Yu, L. S., and M. M. Rienecker, 1999: Mechanisms for the Indian Ocean warming during the 199798 El Niño. Geophys. Res. Lett., 26, 735-738.

Yu L. S, and M. M. Rienecker, 2000: Indian Ocean warming of 1997-1998. J. Geophys. Res., 105, 16923-16939.

Zebiak, S. E., 1989: Ocean heat content variability and El Niño cycles. J. Phys. Oceanog., 19, 475-486. 